\title{
MATERIALS SELECTION FOR WET CYLINDER LINER
}

\author{
M.F. Ahmad Fakaruddin ${ }^{1}$, A. Mohd Hafiz ${ }^{1}$ and K.Karmegam*,2 \\ ${ }^{I}$ Department of Mechanical Engineering, Polytechnic of Sultan Azlan Shah, 35950 Behrang, Perak, Malaysia \\ ${ }^{2}$ Department of Environmental and Occupational Health, Faculty of Medicine and Health Sciences, Universiti \\ Putra Malaysia, 43400 UPM Serdang, Selangor, Malaysia
}

\begin{abstract}
Introduction: Cylinder liner is used in engine block to give a wear protective surface for piston and piston rings. Problem statement: However, continuous exposure to high pressure, high temperature, vibration and friction inside combustion chamber could damage and reduce cylinder liner efficiency. Objective: Therefore, the purpose of this study is to find a suitable material for cylinder liner that can withstand the stated constraints. Methods: By using Cambridge Engineering Software (CES), a list of candidate materials was compared to each other in terms of general properties, mechanical properties, thermal properties and material processing energy. Results: The results provided a list of 5 suitable material (Carbon Steel, Cast PH Stainless Steel, Cast Nickel-Chromium Alloy, Low Alloy Steel and Wrought PH Stainless Steel) for the cylinder liner. Conclusions: Finally, as based on the critical characteristics (durability, composition and operation in exterme combustion), Cast Nickel-Chromium Alloy, Inconel 713C, as cast was indentified as the most suitable material for the wet cylinder liner application.
\end{abstract}

Keywords - cylinder liner, material, combustion, mechanical properties

\section{Introduction}

A cylinder liner or also known as sleeve (Figure 1) is a cylindrical component that is placed in an engine block to form a cylinder. It is an important part because it gives a wear protective surface for piston and piston rings. There are two types of liner which are wet liner and dry liner. Wet liner will contact with coolant while dry liner will contact directly with cylinder block. Among important functions of cylinder liners are to form a sliding surface, to transfer heat and to compress a gas.

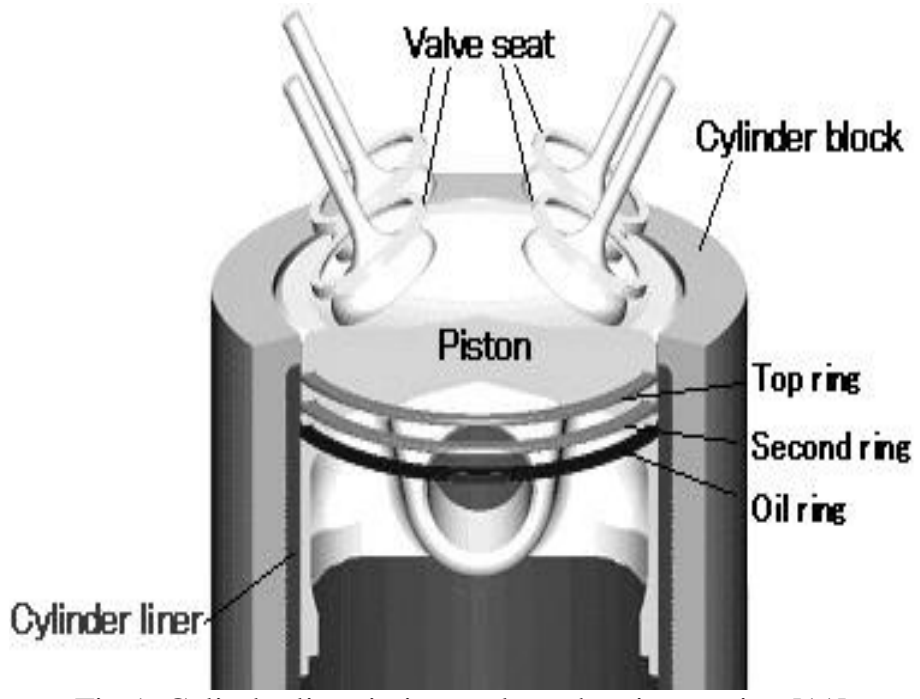

Fig.1. Cylinder liner in internal combustion engine [11]

\section{i. To form a sliding surface}

The cylinder liner will act as an inner wall of the cylinder to form a sliding surface for the piston rings. The main characteristics that cylinder liner should have are high wear resistance properties and less lubricant consumption. [11]

\section{ii. To transfer heat}

Heat from combustion chamber will be transferred to the coolant through cylinder liner (Figure 2). 


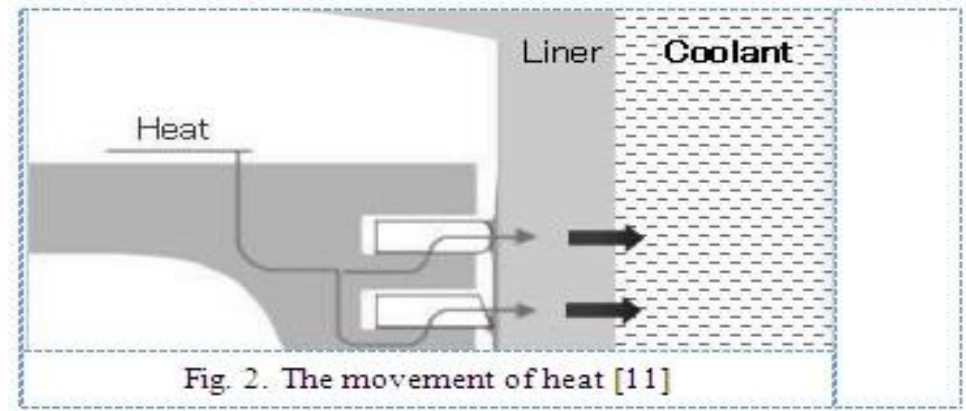

\section{iii. Compression function}

Internal combustion engine needs to have a closed area to be able to get a compression. Together with piston ring, the cylinder liner will provide this as combustion gas couldn't escape outside (Figure 3). It is necessary for the cylinder liner to be hard because of the nature of high pressure and high temperature in the combustion chamber with high sliding speeds of piston and piston rings.

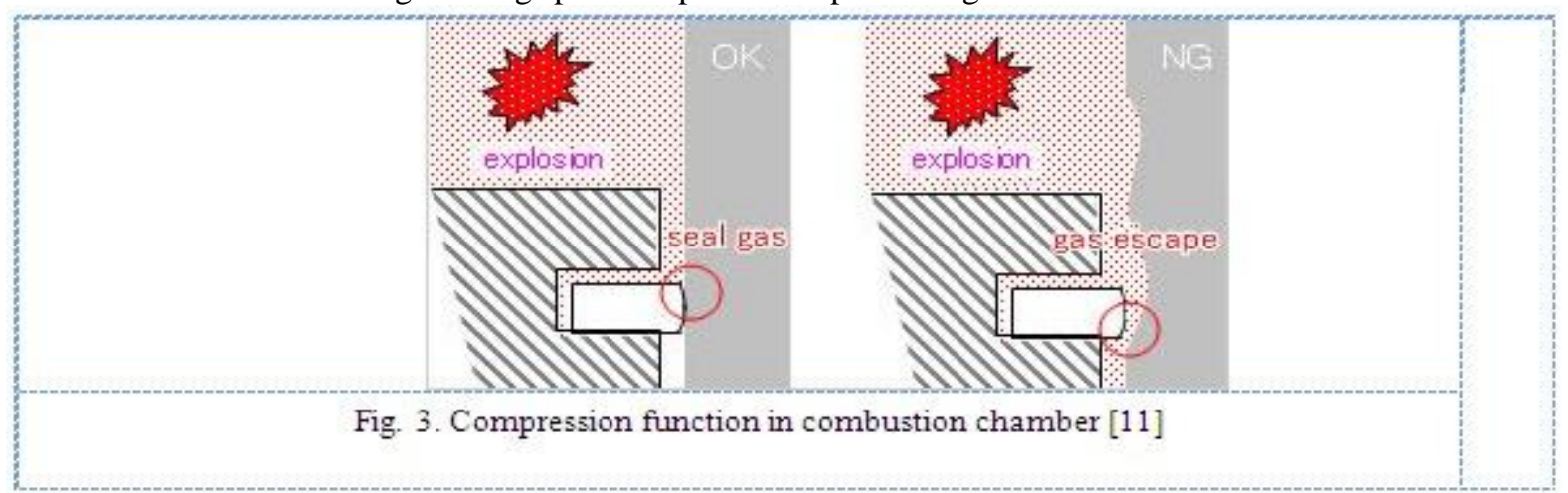

\section{Current Materials for Cylinder Liner}

The current markets usually use is grey cast iron with lamellar graphite (ASTM Grade 40) with pearlitic type microstructure. Aluminium alloy also use in certain applications as mention in reference [10]. Liner materials were usually from different alloys of cast iron, such as phosphorous, titanium and vanadium (Figure 4).

\begin{tabular}{|c|c|c|c|c|c|c|c|c|c|}
\hline $\mathrm{C}$ & $\mathrm{Si}$ & $\mathrm{Mn}$ & $\mathrm{S}$ & $\mathrm{Cr}$ & $\mathrm{Ni}$ & $\mathrm{Mo}$ & $\mathrm{V}$ & $\mathrm{Cu}$ & $\mathrm{Al}$ \\
\hline 3.5 & 1.9 & 0.73 & $<0.2$ & 0.23 & 0.07 & 0.31 & 0.015 & 0.27 & $<0.01$ \\
\hline
\end{tabular}

Fig. 4. Composition of cylinder liner [10]

\section{Problem Statement}

Cavitation is identified as a major contribution to liner damage caused by dynamic deformation of the liner wall. It is mainly due to vibration from piston slap and/or combustion pressure. [10]

The other failure types include wall cracking, corrosion, cavitation erosion and excessive wear. In an operating temperature ranging from room to $2300^{\circ} \mathrm{F}$, a pearlitic casting will expand $1 \%$, which could produce tensile stresses of up to $200 \mathrm{ksi}$ when cooling down. This continuous cyclic straining together with high temperature creep yielding is a progressive failure which is also known as thermal fatigue. [9]

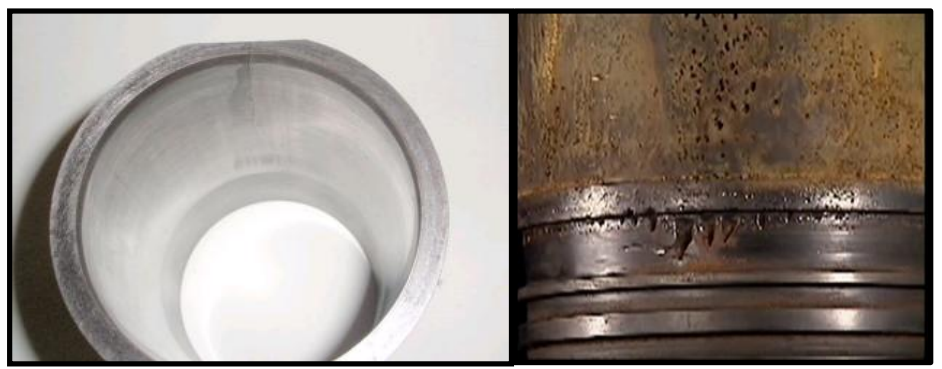

Fig. 5. Liner damages cause by wall cracking, corrosion, cavitation erosion and excessive wear [12] 


\section{Design Approach}

The suitable material for the application of cylinder liner should withstand few important constraints such as:

i. High yield strength (280 MPa) due to exposure to high combustion pressure (5.5 MPa to 8.5 MPa)

ii. High stiffness (200 GPa) due to vibrations

iii. High working temperature $\left(500^{\circ} \mathrm{C}\right.$ to $\left.2000^{\circ} \mathrm{C}\right)$

iv. High wear resistance (300 Vickers Hardness) due repeated friction cycle with piston ring (working hour: 12,000 hour)

v. Good fracture toughness (25 MPam1/2)

vi. Competitive price (between RM 30/kg to RM 40/kg)

\section{Objective:}

The objective of this study is to find a suitable material for cylinder liner that fulfils the constraints stated for the wet type's cylinder liner (used in diesel engine vehicle).

\section{Methodology}

Six filtration stages implemented in this materials selection are:

Stage 1: Fracture Toughness vs. Yield Strength

Stage 2: Tensile Strength vs. Young's Modulus

Stage 3: Thermal Conductivity vs. Maximum Operating Temperature

Stage 4: Wear Resistance

Stage 5: Hardness vs. Machining Energy

Stage 6: Price

\section{Stage 1: Mechanical Factor (Fracture Toughness vs. Yield Strength)}

In every manufactured component, defect is unavoidable. One of it is flaws. The design and choice of material must ensure that they do not propagate. So, fracture toughness of liner is important to resist the flaws (Figure 6). While yield strength is attribute to measure elastic limit before changing to plastic deformation.

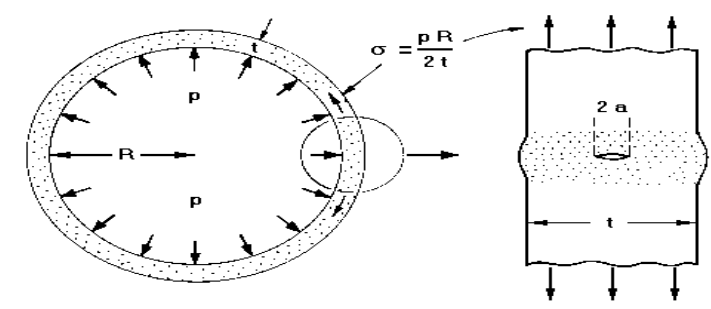

Fig. 6. A cylinder liner pressure in combustion chamber with pre-exist flaws assumption.

The maximum pressure is carried most safely by materials with the large values of

$$
\begin{gathered}
\mathrm{M}_{1}=\frac{\mathrm{K}_{\mathrm{IC}}{ }^{2}}{\sigma_{\mathrm{y}}} \\
\text { Or } \\
\log _{10} \mathrm{M}_{1}=\log _{10} \mathrm{~K}_{\mathrm{IC}}{ }^{2}-\log _{10} \sigma_{\mathrm{y}} \\
\log _{10} \mathrm{~K}_{\mathrm{IC}}=1 / 2 \log _{10} \mathrm{M}_{1}+1 / 2 \log _{10} \sigma_{\mathrm{y}}
\end{gathered}
$$

\section{Stage 2: Mechanical Factor (Tensile Strength vs. Young's Modulus)}

Based on previous research, cavitation is identified as a major contribution to liner damage caused by dynamic deformation of the liner wall (Figure 7 and Figure 8). It is mainly due to vibration from piston slap and/or combustion pressure. Accordingly, the best way to prevent erosion would be to increase the rigidity of the cylinder liner [10]. Therefore, higher value of Young's Modulus is desirable for higher stiffness. Tensile strength is also important to resist high combustion pressure towards liner wall.

The combustion pressure of the gases against the inner surface of the liner was calculated using the equations. The value obtained was 12.5 MPa, uniformly distributed along a distance of the liner. [10]

$$
\begin{gathered}
M_{1}=\frac{\sigma_{f}}{E} \\
\log _{10} M_{1}=\log _{10} \sigma_{f}-\log _{10} E
\end{gathered}
$$


The Young's Modulus can therefore be maximised by maximising the index.

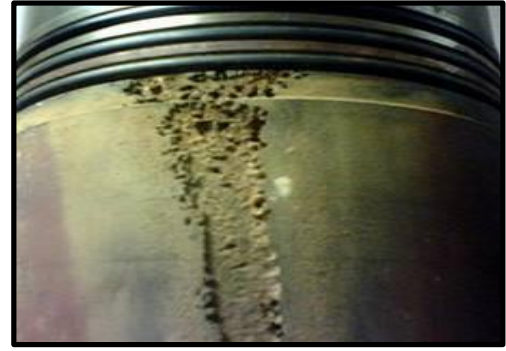

Fig. 7 Cavitations [12]

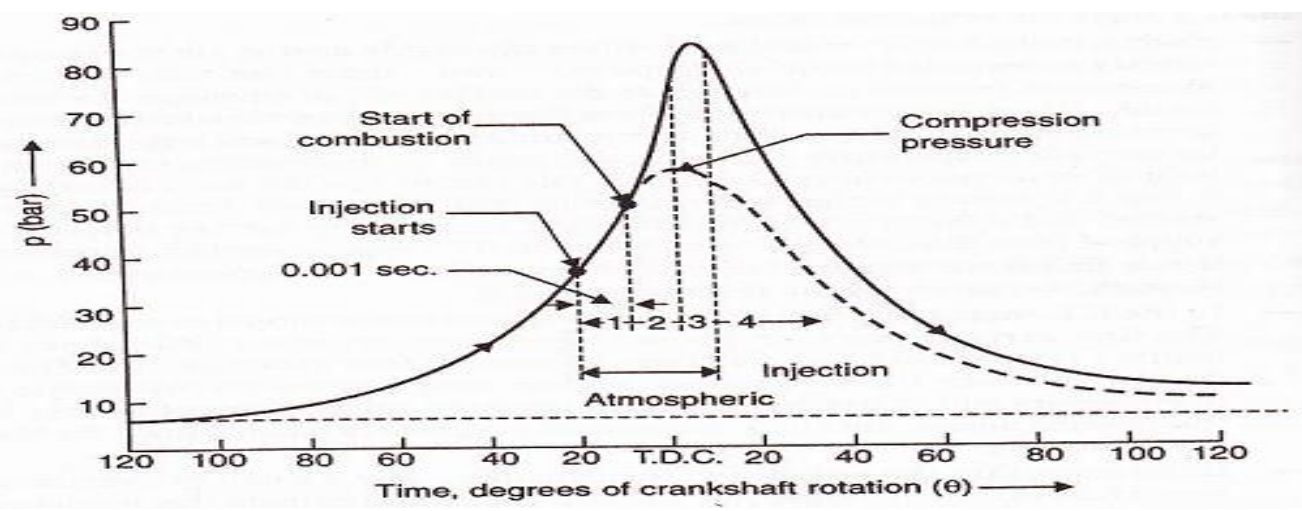

Fig. 8. Combustion pressure in compression ignition engine [8]

\section{Stage 3: Thermal Factor (Thermal Conductivity Vs Maximum Service Temperature)}

The thermal distributions throughout cylinder liner are shown in Figure 9. The temperature varies from $82^{\circ} \mathrm{C}$ up to $154^{\circ} \mathrm{C}$ with help of coolant flow between outside wall and cylinder block. However, the temperature in combustion chamber usually ranging between $500^{\circ} \mathrm{C}$ to $2000^{\circ} \mathrm{C}$ [8]. So for safety reason, a higher value is desirable in case if coolant fails to transfer the heat from combustion chamber efficiently. The highest temperature thermal stress which is red in colour occurs near grooves. Maximum operating temperature is set for materials that could work in between $300^{\circ} \mathrm{C}$ to $2000^{\circ} \mathrm{C}$. Thermal conductivity is a rate at which heat is conducted through a solid at 'steady state'. It means that the temperature profile does not change over time [14]. Uncontrolled temperature could eventually damage the liner. So, it is set between $10 \mathrm{~W} / \mathrm{m} . \mathrm{K}$ to $70 \mathrm{~W} / \mathrm{m} . \mathrm{K}$.
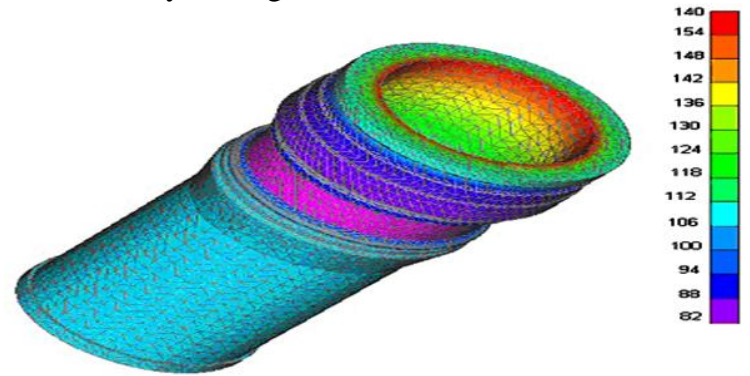

Fig. 9. Temperature distributions [3]

\section{Stage 4: Durability Factor (Wear Resistance)}

Cylinder liner needs to be hard enough because of repeating friction with piston ring. It is rather more important if need to use at higher rpm for longer service time, say 12, 000 hours before giving significant problems.

\section{Stage 5: Processability Factor (Hardness vs. Machining Energy)}

Hardness is the ability of material to resist wear. [14] It is good characteristic for liner if combine with wear resistance. However, harder material makes it hard to be machined, thus require harder tool steels for machining process. Typical manufacturing processes for cylinder liner including casting and machining for surface finish. So it is important to consider values that suitable for both attribute. Based on Figure 10, hardness is set to be above 300 Vickers Hardness and as for machining energy; it is set at range between $4 \mathrm{MJ} / \mathrm{kg}-6$ $\mathrm{MJ} / \mathrm{kg}$. 


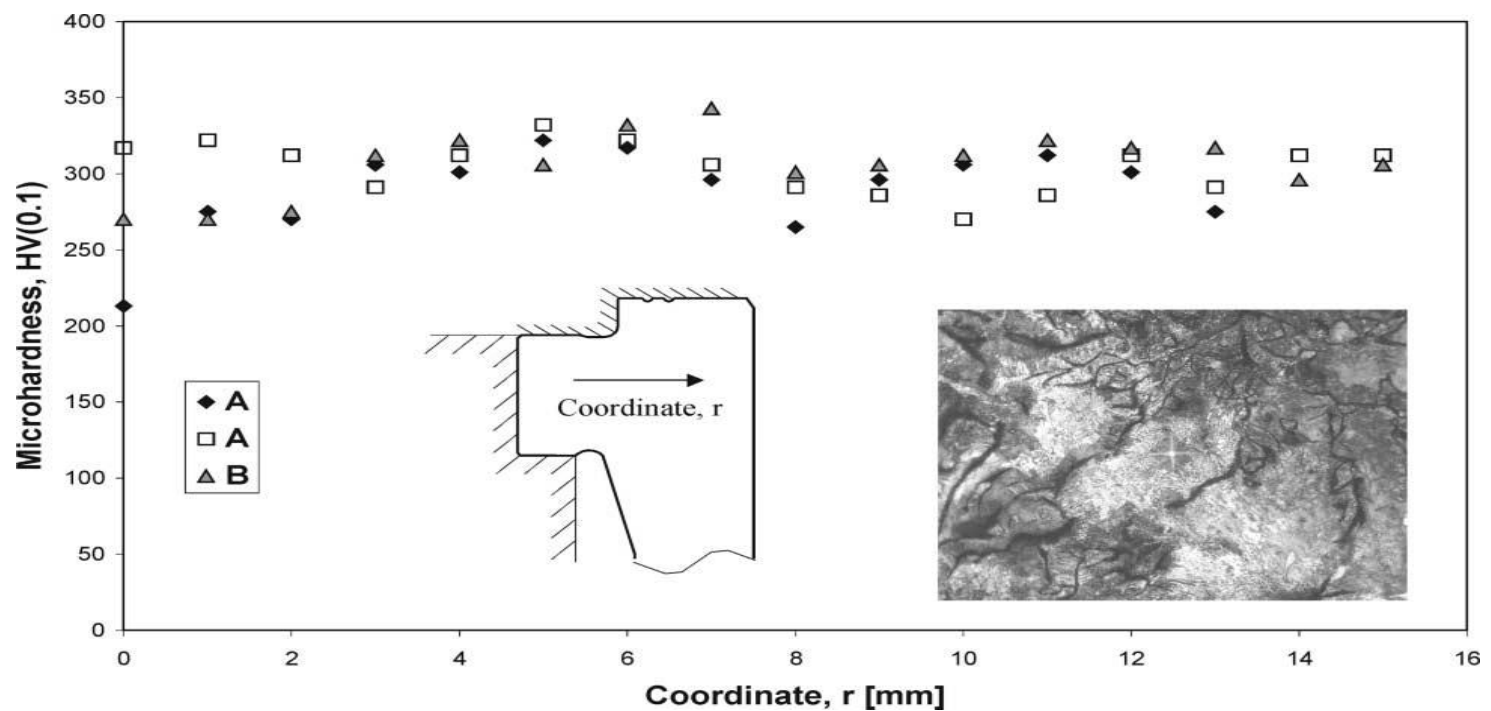

Fig. 10. Variation of Vickers micro hardness along the thickness of the liner [10]

\section{Stage 6: Competitive Price}

Although price tag is a minor constraint, cost will bring another issue in design consideration and perhaps cost is the most demanding item that a manufacturer will looking at after all the analysis has been done. Survey from local market (TTRW Industries Sdn. Bhd., Taiping, Perak) indicates price for cylinder liner ranging from RM 60 to RM 80 per piece for weight of $2 \mathrm{~kg}$. Therefore, it is good to find materials that lower than RM 40/kg.

\section{Material Selection Process}

\section{Results}

\section{Stage 1: Mechanical Factor (Fracture Toughness vs. Yield Strength)}

The desirable fracture toughness is set at $25 \mathrm{MPam}^{1 / 2}$ when Yield strength $=240 \mathrm{MPa}$. This value is based on current materials used for liner which means higher value indicates better characteristics.

Fracture Toughness over Yield Strength is shown in Figure 11. All materials equal to gradient line or above meet the requirement. As based on the results Stage 1: Fracture Toughness (MPa.m ${ }^{1 / 2}$ ) vs. Yield Strength (MPa), a total of 1253 from 1685 materials which fulfil the required requirement is selected.

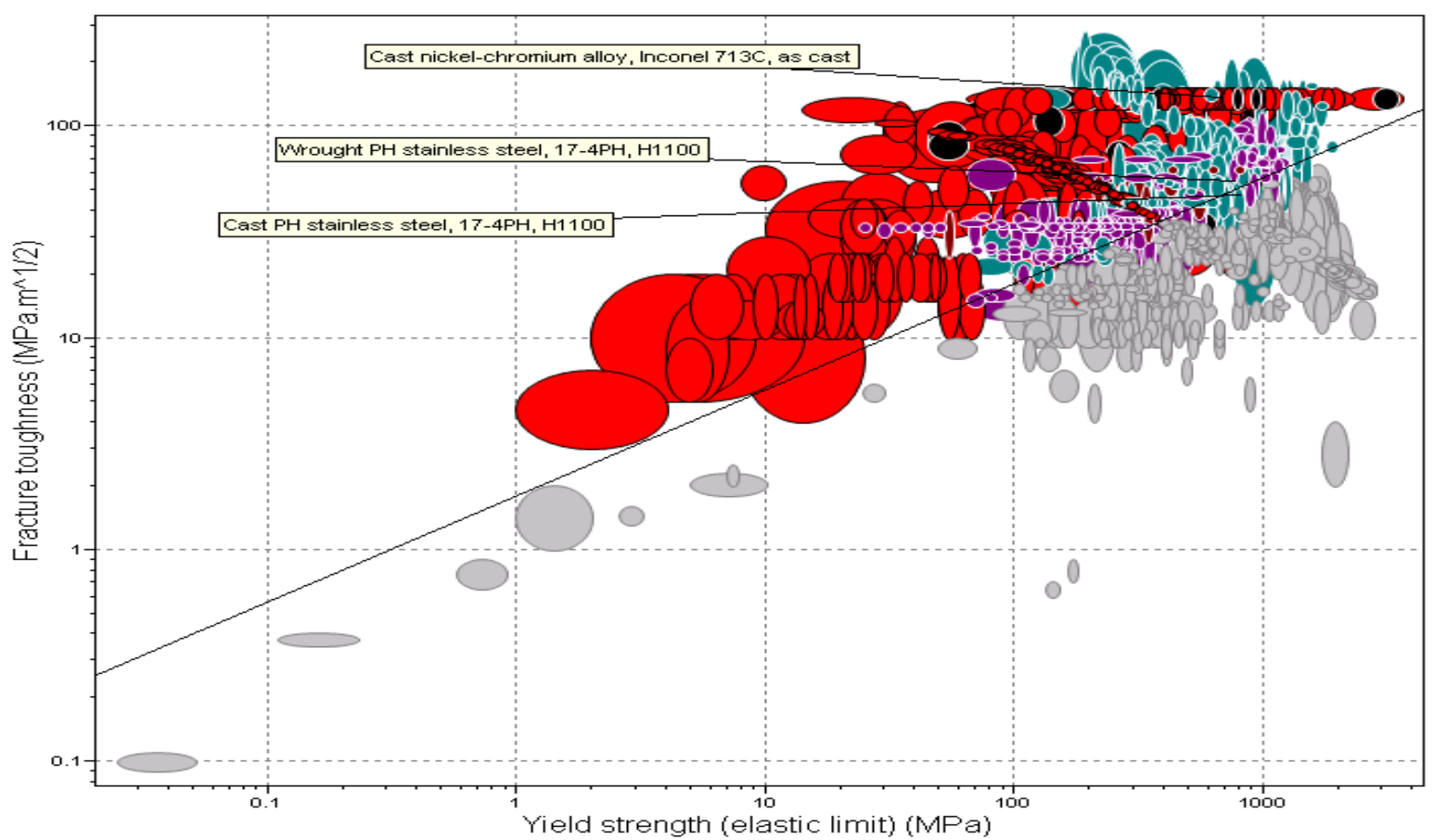

Fig. 11. Stage 1 


\section{Stage 2: Mechanical Factor (Tensile Strength vs. Young's Modulus)}

In normal operations the pressure is around $5.5 \mathrm{MPa}$ to $8.5 \mathrm{MPa}$ (Figure 12), but it also depends on other factor such as fuel-air mixture. In more extreme conditions, pressure could be as high as 12.5 MPa [10]. Therefore, cylinder liner should be able to withstand the pressure. By using equation 2.1, we could determine the slope line. Chosen value for tensile strength is greater than $280 \mathrm{Mpa}$ and Young's Modulus greater than 200 GPa.

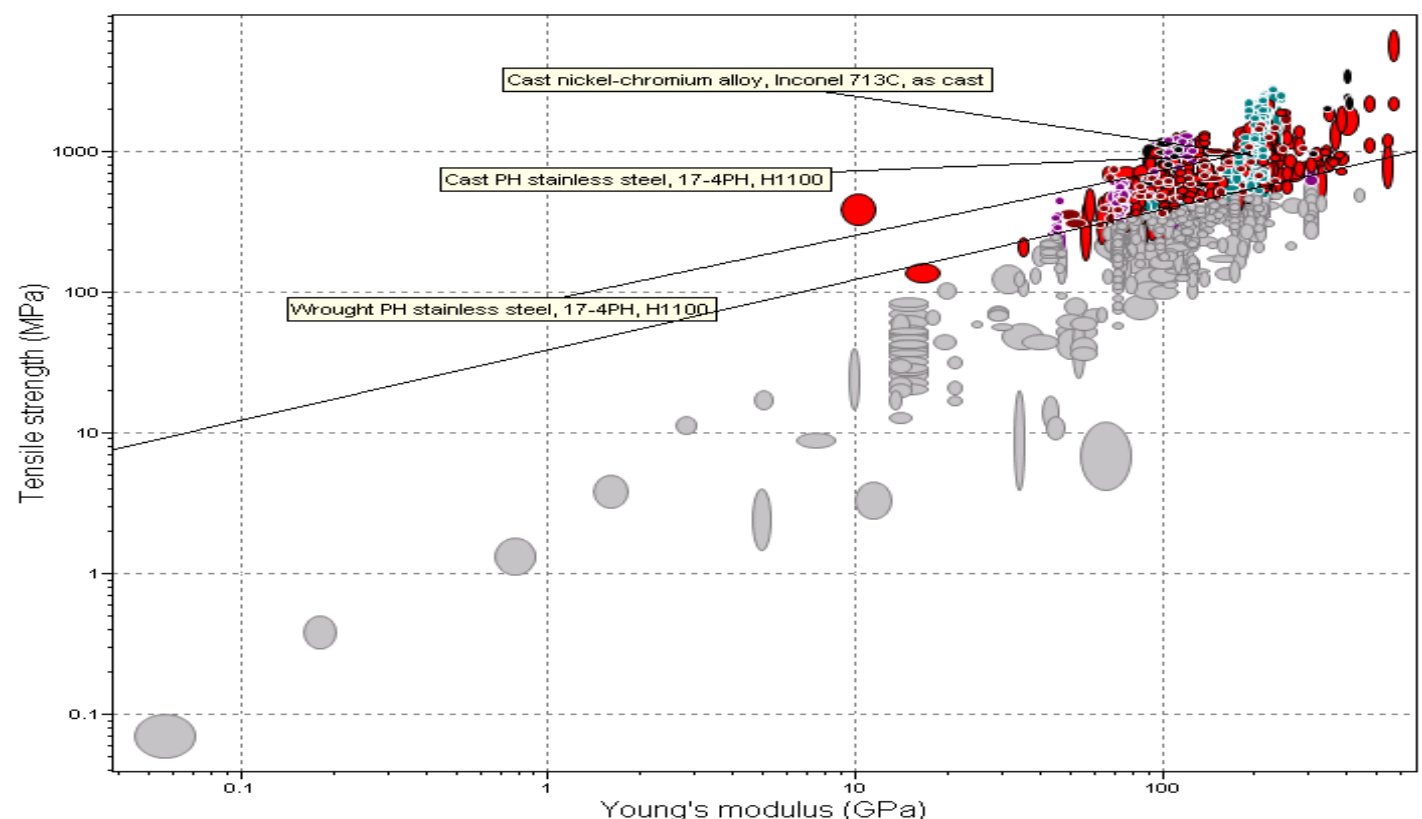

Fig. 12. Stage 2

As based on the results Stage 2: Tensile Strength (MPa) vs. Young's Modulus (GPa), a total of 1197 from 1685 materials has been selected.

\section{Stage 3: Thermal Factor (Thermal Conductivity Vs Maximum Service Temperature)}

For maximum operating temperature (Figure 13), materials that could work in between $300^{\circ} \mathrm{C}$ to $2000^{\circ} \mathrm{C}$ with higher melting point has been set [8]. Thermal conductivity is a rate at which heat is conducted through a solid at 'steady state'. It means the temperature profile does not change over time. [15] It is set between $12 \mathrm{~W} / \mathrm{m} . \mathrm{K}$ to $70 \mathrm{~W} / \mathrm{m} . \mathrm{K}$.

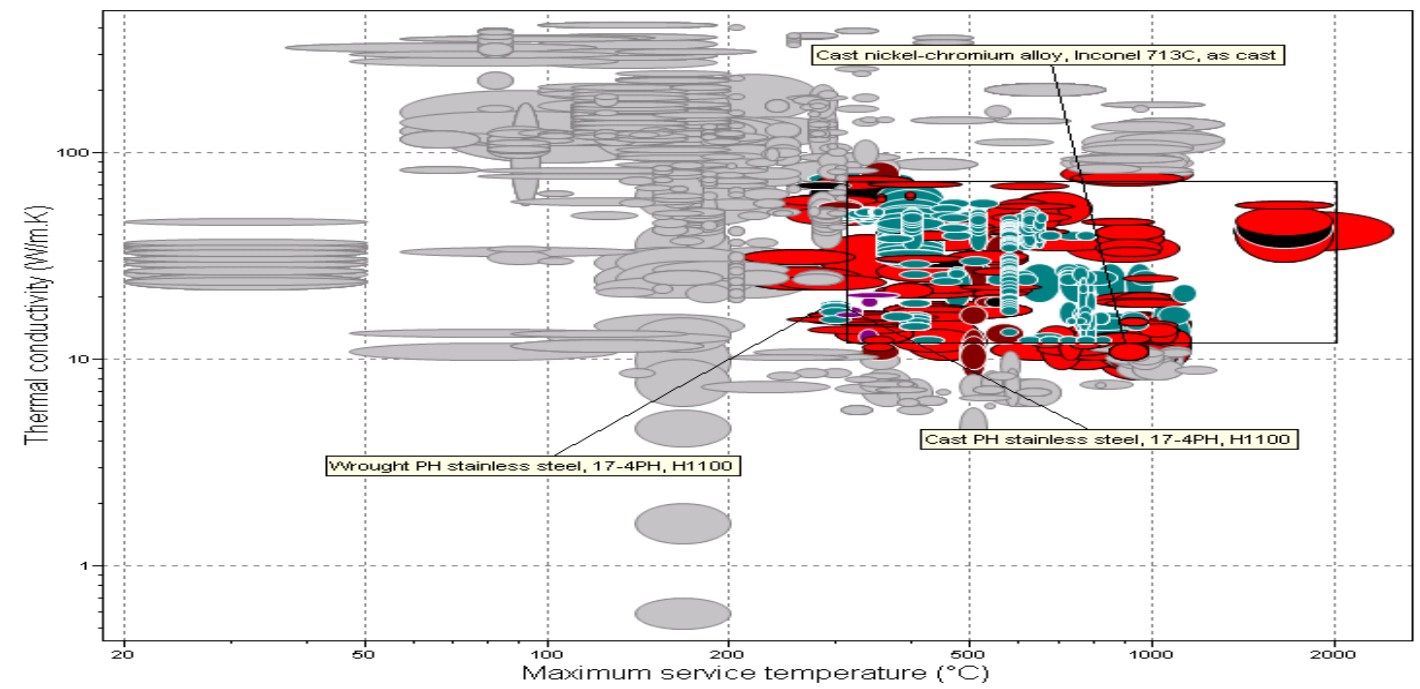

Fig. 13. Stage 3 
As based on the results Stage 3:Thermal Conductivity (W/m.K) vs. Maximum Service Temprature $\left({ }^{\circ} \mathrm{C}\right)$, a total of 782 from 1685 materials has been selected.

\section{Stage 4: Durability Factor (Wear Resistance)}

Cylinder liner needs to be hard enough because of repeating friction with piston ring (Figure 14). It is rather more important if need to use at higher rpm for longer service time, such as 12,000 hours before giving significant problems. Materials at a very good area are needed to be selected. As based on the results Stage 4: Wear Resistance, a total of 801 from 1685 materials has been selected.

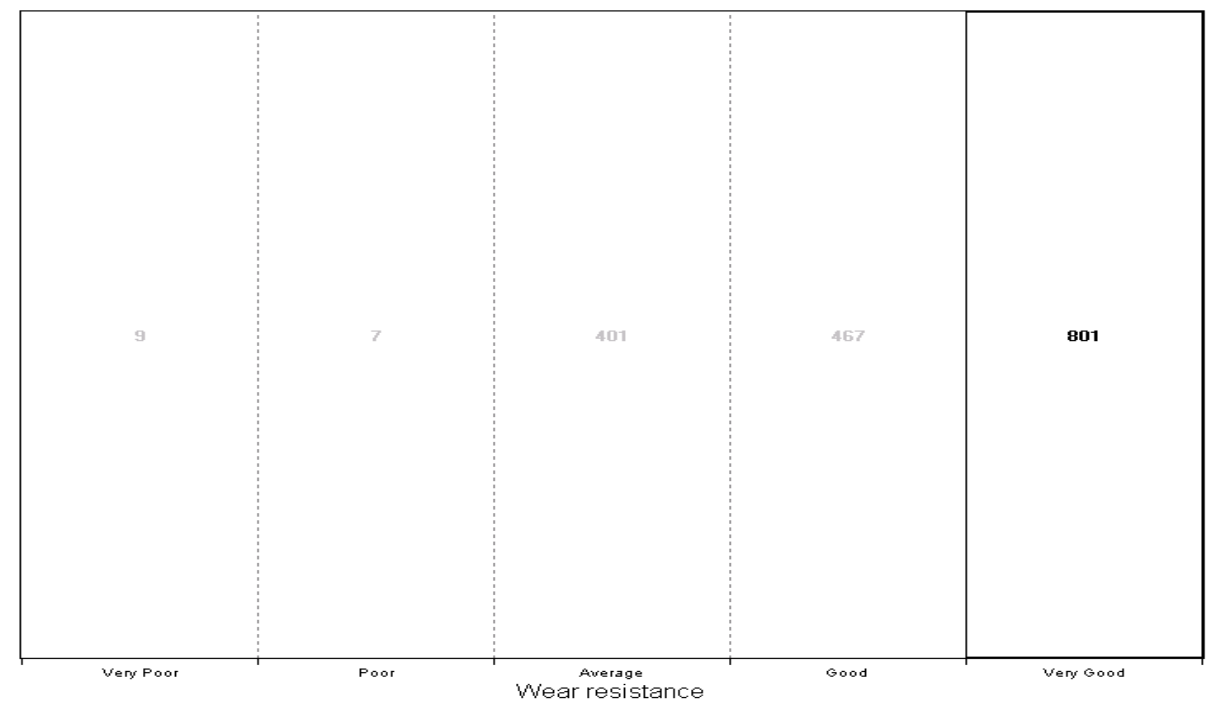

Fig. 14. Stage 4

\section{Stage 5: Processability Factor (Hardness vs. Machining Energy)}

Hardness is good characteristic if combine with wear resistance. However, typical manufacturing process for cylinder liner includes casting and machining for surface finishing. So it is important to consider a value that suitable for both attribute. Hardness is set to be above 300 Vickers Hardness and as for machining energy; it is set at range between $4 \mathrm{MJ} / \mathrm{kg}-6 \mathrm{MJ} / \mathrm{kg}$. As based on the results Stage 5: Hardness - Vickers (HV) vs. Machining Energy (MJ/kg), a total of 145 from 1685 materials has been selected (Figure 15).

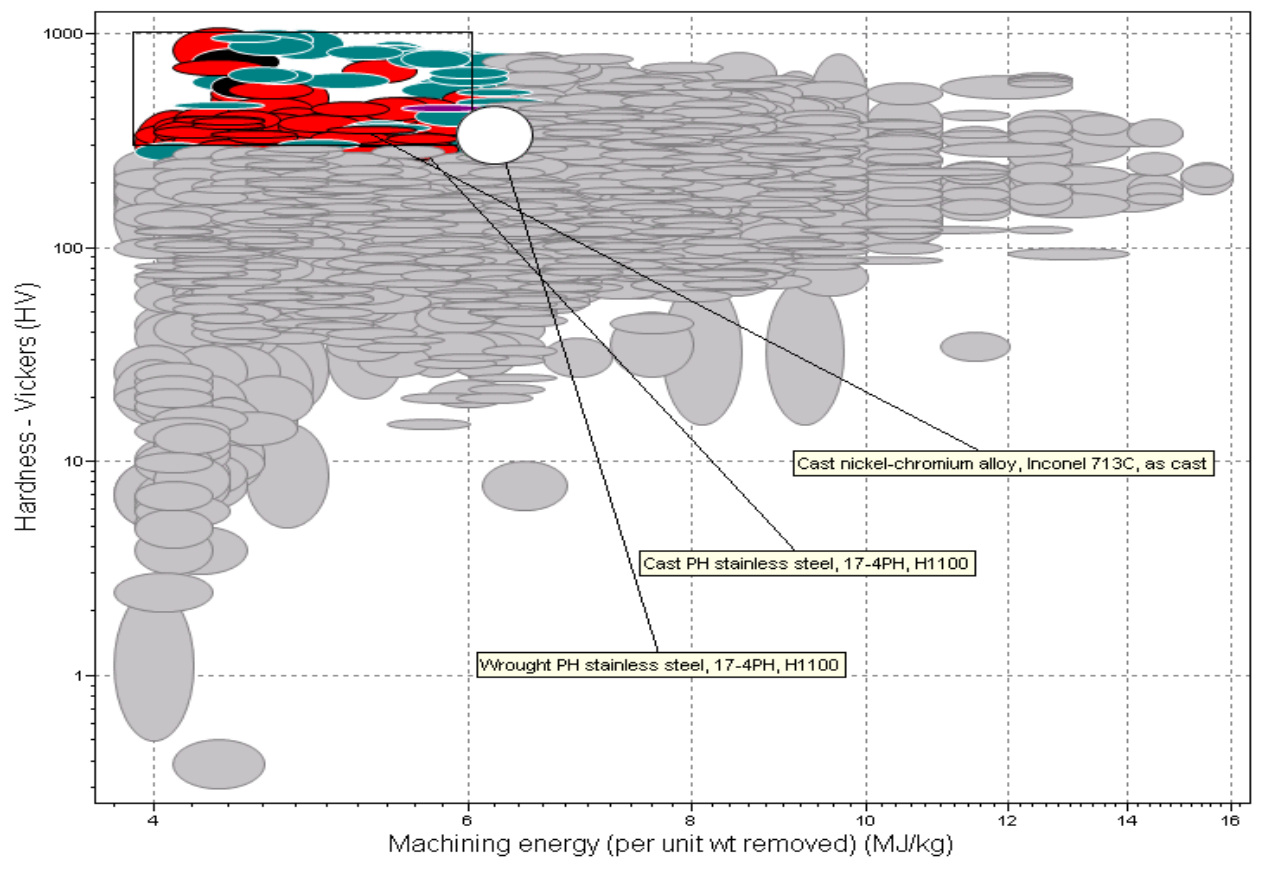

Fig. 15. Stage 5 


\section{Stage 6: Competitive Price}

The price range is set at the market price and below (RM 40/kg). It means that it is a good price with good characteristics. As based on the result Stage 6: Price (MYR/kg), a total of 1173 from 1685 materials has been selected (Figure 16).

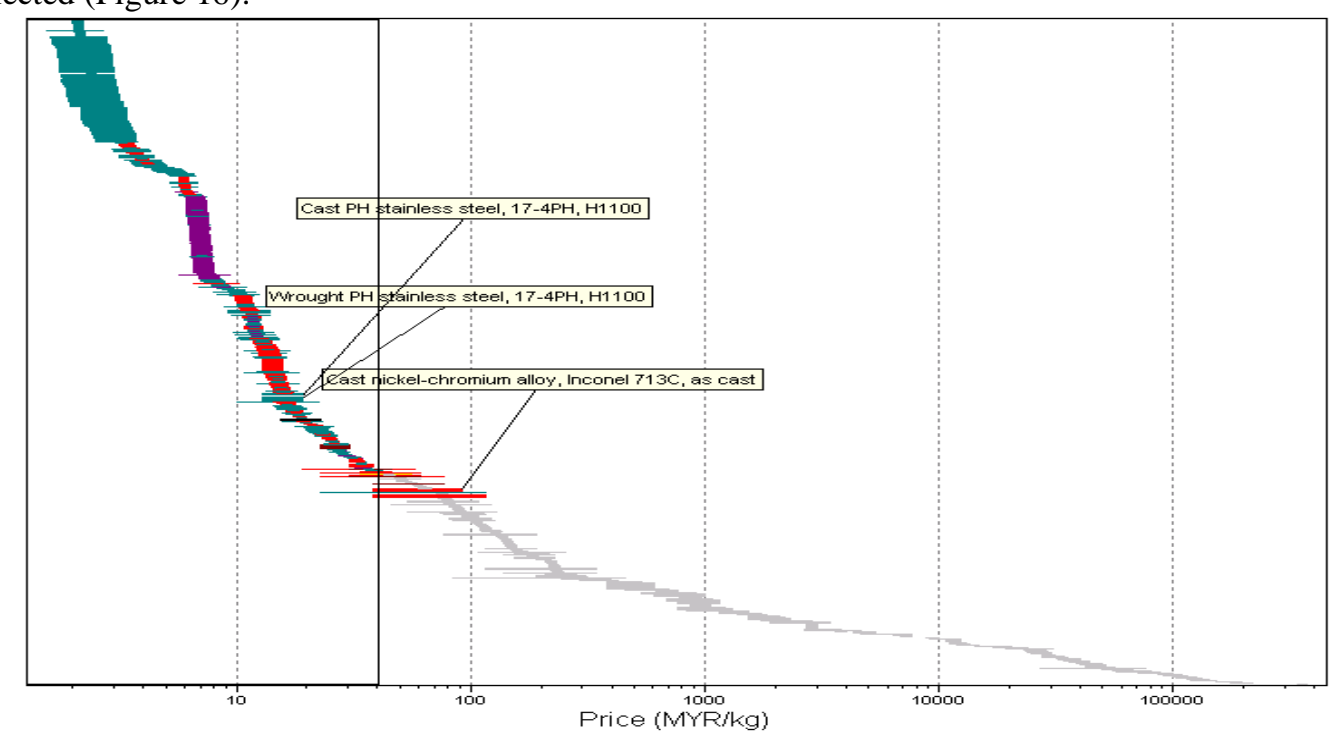

Fig. 16. Stage 6

\section{Discussion}

The environment in which the materials will operate plays an important factor in determining the material performance requirements. Corrosive environments, as well as high temperatures, can hugely affect the performance of most materials in service.

The most important characteristic in designing wet cylinder liner is by considering the stiffness aspects. Previous research has identified that cavitation is the main cause of liner wall damage due to vibration from piston slap and/or combustion pressure. [10] Therefore, the best way to prevent the erosion would be to increase the rigidity of the cylinder liner. As this, in process of the material selection, the highest value of Young's Modulus was seen in the Cast Nickel-Chromium Alloy, Inconel 713C, as cast with estimated range of $200 \mathrm{GPa}$ to $216 \mathrm{GPa}$ (average $208 \mathrm{GPa}$ ). However, it is not much different with other candidates. Carbon steel, AISI 1095 (as rolled) is the closest with average $207.5 \mathrm{GPa}$. Other mechanical properties such as surface hardness should also need to be considered as well. Again, this vital characteristic was shown in Cast Nickel-Chromium Alloy, Inconel 713C, as cast with the value of $300 \mathrm{HV}-420 \mathrm{HV}$ (Average $360 \mathrm{HV}$ ). Although Low Alloy Steel, AISI 4135, Normalized gives the highest value (499.99 HV), the huge range make the average $333.25 \mathrm{HV}$.

Another mechanical property that should be considered is the fracture toughness. It is again goes to Cast Nickel-Chromium Alloy, Inconel 713C, as cast leaving other material competitors far behind. Other mechanical properties that should not be ignored are bulk modulus, tensile strength and yield strength. However wear resistance are considered same for all the materials as shown earlier in the result of Stage 4.

Although thermal factor doesn't have huge influence as the mechanical factor due to the help of the coolant, it is still useful to be considered. The comparison was made comprise three thermal factors such as maximum service temperature, thermal conductivity and melting point. All of the five candidate's material fulfils the maximum service temperature which is about $300^{\circ} \mathrm{C}$. Also all of the five candidate materials have melting points above $1260^{\circ} \mathrm{C}$ which consider good for liner application. This melting point however relies on the heat transfer of engine cooling and lubricating system.

Another thermal factor that should be considered is the thermal expansion. The materials with lowest thermal expansion coefficient shall be selected because if the material expands too high it could build up stress in the liner during contact between piston ring and cylinder block [4]. Cast Nickel-Chromium Alloy, Inconel $713 \mathrm{C}$, as cast has the lowest thermal expansion coefficient with $9.5 \mu$ strain $/{ }^{\circ} \mathrm{C}$ to $12 \mu$ strain $/{ }^{\circ} \mathrm{C}$.

The final five materials are selected and compared each other in term of their properties (Table 2). All of these materials have been passed the filtration stages. 


\begin{tabular}{|c|c|c|c|c|c|c|}
\hline & Properties & $\begin{array}{l}\text { Carbon } \\
\text { Steel, AISI } \\
1095 \text { (as } \\
\text { rolled) }\end{array}$ & $\begin{array}{l}\text { Cast PH } \\
\text { Stainleas } \\
\text { Steel, } 17- \\
4 \mathrm{PH}, \\
\text { H1100 }\end{array}$ & $\begin{array}{l}\text { Cast Nickel- } \\
\text { Chromium } \\
\text { Alloy. } \\
\text { Inconel } \\
713 \mathrm{C}, \text { as } \\
\text { cast }\end{array}$ & $\begin{array}{l}\text { Low Alloy } \\
\text { Stael, AISI } \\
4135 \text {. } \\
\text { Nomalizad }\end{array}$ & $\begin{array}{l}\text { Wrought PH } \\
\text { Stainless } \\
\text { Steel, } 17 \text {. } \\
\text { 4PH, H1100 }\end{array}$ \\
\hline \multirow[b]{2}{*}{ General } & Density $\left(2 z^{\prime} 3\right)$ & $7800-7900$ & $7822-7900$ & $7800-8000$ & $7794-7873$ & $7822-7900$ \\
\hline & Price (ACYR kg) & $1.94-3.27$ & $\begin{array}{l}1302:- \\
19.15 \\
\end{array}$ & $383-9192$ & $217-3.39$ & $1302-19.15$ \\
\hline \multirow{6}{*}{ Mechanical } & Bulk: Modulus (GPa) & $155-175$ & $1424-150$ & $155-185$ & $185.1-194.6$ & $1424-150$ \\
\hline & $\begin{array}{l}\text { Fracture Toughness } \\
\text { (Pa m } 1 / 2)\end{array}$ & $45-76$ & $40-65$ & $120-150$ & $90-110$ & $40-65$ \\
\hline & Hardnest-Vickers (HV) & $270-330$ & $250-460$ & $300-420$ & 16664999 & $250-360$ \\
\hline & Tensile Strength ( $\left(\mathrm{Pa}_{\mathrm{a}}\right)$ & $865-1070$ & $896-9903$ & $755-990$ & $621-690$ & $965-1067$ \\
\hline & Yield Strangh (MPa) & $510-635$ & $827-914.1$ & $685-900$ & $483-586$ & $793-876.5$ \\
\hline & Young's MCodulus (GPa) & $200-215$ & $197-207.1$ & $200-216$ & $200-2103$ & $197-207.1$ \\
\hline \multirow{4}{*}{ Thermal } & $\begin{array}{l}\text { Maximum Service } \\
\text { Temperature ("C) }\end{array}$ & $273-336$ & $282-316$ & $852-982$ & $470-524$ & $282-316$ \\
\hline & Melting Point (C) & $1289-1465$ & $1400-1440$ & $1260-1290$ & $1256-1578$ & $1400-1440$ \\
\hline & $\begin{array}{l}\text { Thermal Conductivity } \\
(W / n \mathrm{~K})\end{array}$ & $47-52$ & $17.3-18.74$ & $10-12$ & $48-52$ & $17.3-18.74$ \\
\hline & $\begin{array}{l}\text { Thernal Expansion } \\
\text { Coefficient (ustrain }=C)\end{array}$ & $11-13.5$ & $125-13.14$ & $9.5-12$ & $1242-13.06$ & $125-13.14$ \\
\hline \multirow{3}{*}{$\begin{array}{l}\text { Material } \\
\text { Processing } \\
\text { Energy }\end{array}$} & CastingEnergy (ND/ $/ \mathrm{g})$ & $3-33$ & $3.1-3.4$ & $2.8-3.1$ & $3.1-3.4$ & $3.1-34$ \\
\hline & $\begin{array}{l}\text { Forging, Rolling Energy } \\
(\mathrm{MU} / \mathrm{kg}\end{array}$ & $6.6-7.3$ & $6.9-7.7$ & $68-7.5$ & $6.2-6.8$ & $7-7.7$ \\
\hline & $\begin{array}{l}\text { Machining Energy } \\
(\mathrm{NU} / \mathrm{h} \mathrm{g})\end{array}$ & $5.8-6.5$ & $5.3-5.8$ & $4.8-5.3$ & $5.7-63$ & $59-6.5$ \\
\hline
\end{tabular}

\section{Conclusion}

Finally, after carefully looking at all of the five possible materials, the most suitable material for wet cylinder liner application was Cast Nickel-Chromium Alloy, Inconel 713C, as cast. This is because it gives the best properties that a cylinder liner should possess such as:

i. Enhanced Durability - possess the highest Young's Modulus, highest fracture toughness, good tensile strength, highest Vickers hardness number and good bulk modulus which could drives towards longer service life.

ii. Composition - High Nickel (68-76\%) and Chromium (12-14\%) composition has proved to be good solution to cavitation failure. [10]

iii. Enables operation in extreme combustion engine that posses maximum service temperature nearly $1000^{\circ} \mathrm{C}$ and moderate melting temperature that could reach about $1260^{\circ} \mathrm{C}$ and have good thermal expansion coefficient.

\section{References}

[1] Branco, C.M., Infante V., Sousa e Brito A. \& Martin R.F. 2001. A failure analysis study of wet liners in maritime diesel engines. Engineering Failure Analysis 9 (2002) 403-421.

[2] Callister, D. C. 2007. Materials Science and Engineering : Introduction. Seventh Edition. York: John Wiley \& Sons Inc.Page 366 - 372.

[3] Espadafor, J.F., Villanueva, J.B., García, M.T., Trujillo, E.C. 2009. Analysis of a diesel generator cylinder failure. Engineering Failure Analysis 17 (2010) 913-925.

[4] Gustof, P., Hornik, A. 2008. Determination of the temperature distribution in the wet cylinder sleeve in turbo diesel engine. Journal of Achievements in Materials and Manufacturing Engineering. Volume 27 Issue 2. 
[5] Heywood, J. B. 1988. Internal Combustion Engine Fundamentals. New York: Mc Graw-Hill Inc. Page 255.

[6] Mohd Hamdi Bin Khosran. 2010 Kajian Penambahbaikan Produktiviti, Kualiti dan Ekonomik Pelapik Silinder Model 2J Toyota Syarikat X. UKM. Page 53.

[7] Mott RL. Tolerances and Fits. Machine elements in mechanical design. USA: Charles Merrill, 1985 (Chapter 8). pp. 178-198.

[8] Rajput, R. K. 2005. Internal Combustion Engine. New Delhi: Laxmi Publications (P) LTD. Page 132

[9] X. L. Xu*, Z. W. Yu and J. Wang, Influences of microstructure on service properties of 5Cr21Mn9Ni4N heat resistant alloy, Materials Science and Technology 2007 VOL 23 NO 8

[10] Yu-Kang Zhou, Jiu-Gen He \& Hammit, F.G.1981. Cavitation Erosion Liners of Diesel Engine Wet Cylinder Liners 76 (1982) $321-328$

[11] http://www.tpr.co.jp/tp_e/products/cylinderliners/about_cylinderliners.html.TPR.CO.LTD.13th December 2010.

[12] http://www.engineeringtoolbox.com/thermal-conductivity-metals-d_858.html.13th December 2010.

[13] CES EduPack 2006. Granta Design Limited. CES InDepth

[14] Evans, B., Potts, W. 2004. A Level Product Design. Cheltenham: Nelson Thornes Ltd. Page 125. 